\title{
Breast tuberculosis presenting with intractable mastitis: a case report
}

\author{
Yuka Sagara', Shuji Hatakeyama ${ }^{1,2^{*}}$, Ayako Kumabe $^{1}$, Masako Sakuragi ${ }^{3}$ and Masami Matsumura ${ }^{1}$
}

\begin{abstract}
Background: Breast tuberculosis, also known as tuberculous mastitis, is an extremely rare form of tuberculosis. It accounts for $<0.1 \%$ of all breast diseases and $<2 \%$ of all cases of tuberculosis. It is often misdiagnosed as breast cancer, which can potentially lead to a delayed diagnosis.

Case presentation: A 69-year-old Japanese woman presented with a tumor-mimicking lesion in her right breast, followed by intractable mastitis with a fistula formation. The time until the correct diagnosis of tuberculosis of the breast and sternal bone was 14 months.

Conclusions: Although rare, it is important to recognize that tuberculous mastitis can present as refractory abscesses/mastitis or mass lesions that mimic carcinomas in women of reproductive age and elderly people. Breast tuberculosis should always be considered in the differential diagnoses, particularly in patients with a history of tuberculosis and those living in areas where tuberculosis is endemic.
\end{abstract}

Keywords: Breast tuberculosis, Tuberculous mastitis, Breast cancer, Fistula, Sternal osteomyelitis

\section{Background}

Infectious mastitis is common in young lactating women, and the major causative bacteria are Staphylococcus aureus and Staphylococcus epidermidis [1]. Periductal mastitis and idiopathic granulomatous mastitis are known as non-lactational mastitis. Periductal mastitis has been reported to be related to a history of smoking and infections caused by anaerobic bacteria, staphylococci, enterococci, and Proteus spp. [2]. Idiopathic granulomatous mastitis might be associated with Corynebacterium kroppenstedtii infections [3].

Mycobacterium tuberculosis is a rare but important causative organism of mastitis, especially in chronic or intractable cases. Breast tuberculosis is difficult to diagnose and is often misdiagnosed as breast cancer. We report here a case of tuberculous mastitis that presented with a thoracic mass, breast fistula, and sternal

\footnotetext{
*Correspondence: shatake-tky@umin.ac.jp

1 Division of General Internal Medicine, Jichi Medical University Hospital,

3311-1 Yakushiji, Shimotsuke-shi, Tochigi 329-0498, Japan

Full list of author information is available at the end of the article
}

osteomyelitis. The patient underwent various examinations and was treated for mastitis with no improvement, and the correct diagnosis was made at 14 months. Written informed consent was obtained from the patient for publishing the case report and images.

\section{Case presentation}

Fourteen months prior to the referral to our institution, a 69-year-old Japanese woman presented at an orthopedic hospital with a painless mass, approximately $10 \mathrm{~mm}$ in diameter, in the right breast adjacent to the sternal border. Based on contrast-enhanced computed tomography (CT) findings, the breast mass was tentatively diagnosed as a benign tumor. However, the lesion gradually increased in size. Four months later, she was referred to the breast surgery department of a community hospital. Ultrasound imaging showed a $17 \mathrm{~mm}$ mass surrounded by fluid in the right breast. Cytology of the needle biopsy specimens revealed nonspecific inflammatory cells without atypical cells. Bacterial cultures of the specimens yielded no pathogens. She was administered cefcapene

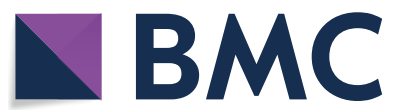

(c) The Author(s) 2021. Open Access This article is licensed under a Creative Commons Attribution 4.0 International License, which permits use, sharing, adaptation, distribution and reproduction in any medium or format, as long as you give appropriate credit to the original author(s) and the source, provide a link to the Creative Commons licence, and indicate if changes were made. The images or other third party material in this article are included in the article's Creative Commons licence, unless indicated otherwise in a credit line to the material. If material is not included in the article's Creative Commons licence and your intended use is not permitted by statutory regulation or exceeds the permitted use, you will need to obtain permission directly from the copyright holder. To view a copy of this licence, visit http://creativecommons.org/licenses/by/4.0/. The Creative Commons Public Domain Dedication waiver (http://creativeco mmons.org/publicdomain/zero/1.0/) applies to the data made available in this article, unless otherwise stated in a credit line to the data. 
pivoxil $100 \mathrm{mg}$ three times a day for 12 days; however, there was no improvement. She was diagnosed with nonspecific (non-purulent) mastitis, and incisional drainage of the lesion was performed.

Eight months later, the breast lesion, which still continued to increase in size, spontaneously discharged pus from the skin around the right nipple. The patient was referred to the breast surgery department at our hospital, and further referred to our department for the treatment of intractable mastitis.

Her medical history revealed miliary tuberculosis at the age of 25 years, for which she had been hospitalized and treated with three drugs, including streptomycin, for 1 year. She had been a homemaker since her twenties, living with her husband. Her socioeconomic status was not low. She had five pregnancies, three abortions, and two live births. She was an ex-smoker with a smoking history of 42 pack-years. Currently, she was taking clopidogrel and aspirin for ischemic heart disease, bisoprolol and enalapril for hypertension, and lovastatin for dyslipidemia. Her family history was unremarkable.

On examination, she appeared well with stable vital signs: body temperature, $36.7^{\circ} \mathrm{C}$; blood pressure, $144 / 76$ $\mathrm{mm} \mathrm{Hg}$; pulse rate, 96 beats per minute; and respiratory rate, 14 breaths per minute. The cervical and axillary lymph nodes were not palpable. Heart sounds were normal without murmurs, and the lung sounds were clear without crackles. Her abdomen was soft and flat with no hepatosplenomegaly. Clinical breast examination revealed palpable cord-like induration with mild tenderness from the right margin of the sternum to the skin around the right nipple. The formation of a fistula was observed near the right nipple, and it showed slightly cloudy and yellowish exudates (Fig. 1a).

The laboratory test results were as follows: white blood cell count, $5200 / \mu \mathrm{L}$; hemoglobin, $11.9 \mathrm{~g} / \mathrm{dL}$; platelet count, $159,000 / \mu \mathrm{L}$; albumin, $4.5 \mathrm{~g} / \mathrm{dL}$; aspartate aminotransferase, $21 \mathrm{U} / \mathrm{L}$; creatinine, $0.65 \mathrm{mg} / \mathrm{dL}$; and C-reactive protein, $0.08 \mathrm{mg} / \mathrm{dL}$ (reference: $<0.06 \mathrm{mg} / \mathrm{dL}$ ). Interferon-gamma release assay (T-SPOT.TB ${ }^{\circledR}$ ) showed positive results. She tested negative for human immunodeficiency virus.

Mammography showed distortion accompanied by retraction of the right nipple with regional microcalcifications. CT revealed high-density lesions suggesting inflammatory changes in the right breast and calcifications of the right apical pleura and mediastinal lymph nodes. Breast magnetic resonance imaging (MRI) showed no mass in the right mammary gland and a fistula formation between the parasternal area and skin of the right breast (Fig. 2a). T2 imaging showed enhanced high signal intensity lesions in the sternum, suggesting sternal osteomyelitis.

Pus drained from the fistula was collected with a clean syringe and immediately sent to the hospital laboratory to test for aerobic and anaerobic bacteria, mycobacteria, and fungus. Although Gram staining, Ziehl-Neelsen staining, and bacterial and fungal cultures showed
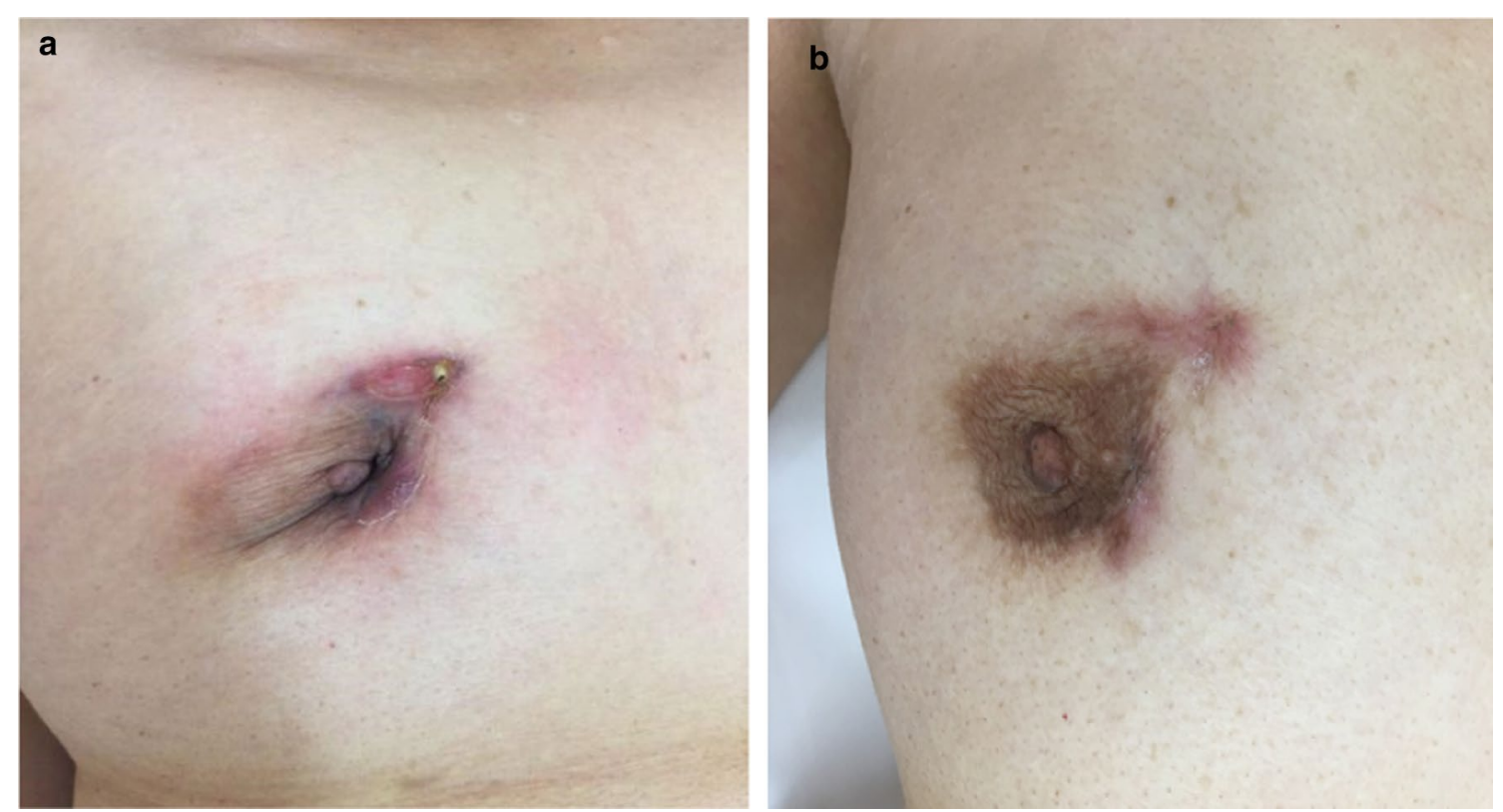

Fig. 1. Appearance of tuberculous mastitis. a Before treatment: a fistula with persistent pus discharge and retraction of the right nipple. $\mathbf{b}$ After completion of anti-tuberculosis treatment: closed fistula and improvement of the deformities in the nipple and areola 

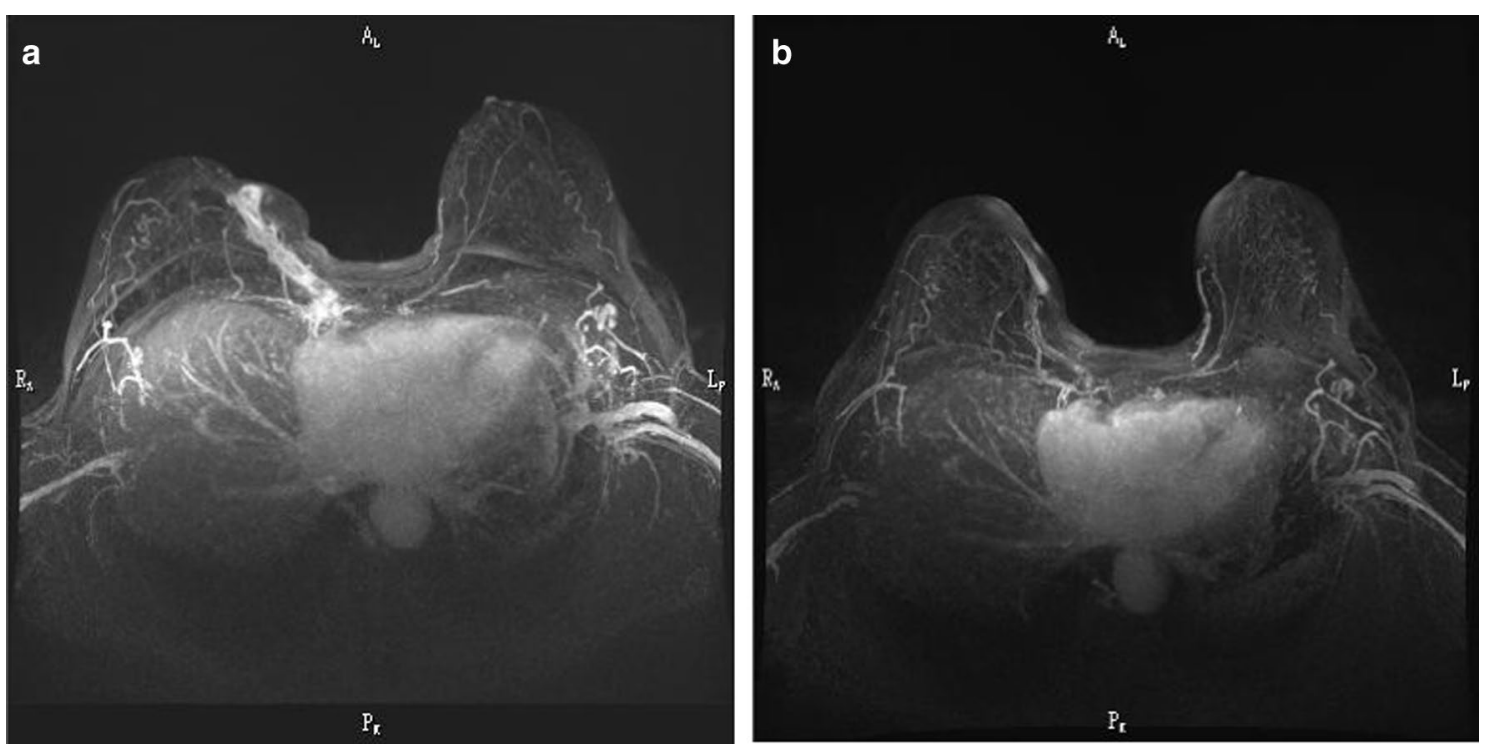

Fig. 2. Dynamic subtraction magnetic resonance imaging of the breast. a Before treatment: formation of a fistula between the parasternal area and skin of the right breast. $\mathbf{b}$ After completion of antituberculosis treatment

negative results, polymerase chain reaction for $M$. tuberculosis was positive. Blood culture was not performed. Four weeks later, the $M$. tuberculosis isolate was cultured from the pus specimen and showed good sensitivity to isoniazid, rifampicin, ethambutol, streptomycin, and levofloxacin. She was diagnosed with tuberculous mastitis and sternal osteomyelitis. A 2-month intensive phase of therapy with isoniazid ( $300 \mathrm{mg}$ daily), rifampicin ( 450 $\mathrm{mg}$ daily), ethambutol (750 mg daily), and pyrazinamide (1200 mg daily) was initiated, followed by 7 -month continuation therapy with isoniazid and rifampicin. After completion of the treatment regimen, the fistula and deformity in the breast were healed (Fig. 1b), and MRI findings of the lesion showed considerable improvement (Fig. 2b). At the 2-year follow-up after treatment, she was cured of the disease and experienced no recurrence or relapse.

\section{Discussion and conclusions}

We experienced a case of refractory mastitis complicated by breast fistula and sternal osteomyelitis, in which a detailed medical history and suspicion of tuberculosis led to the definitive diagnosis and treatment of breast tuberculosis. Breast tuberculosis is a rare condition, accounting for less than $0.1 \%$ of all breast diseases and $1.1 \%$ of all cases of tuberculosis [3-5]. In endemic countries such as India, tuberculous mastitis has been reported to account for up to 3\% of surgically treated breast diseases [6]. Usually, tuberculous involvement of the breast is considered to develop following lymphatic invasion from the parasternal, mediastinal, axillary, or cervical lymph nodes [5,
7]. In addition, hematologic spread from remote lesions or direct extension from the adjacent skin lesions might also occur [4]. Lactation, which involves increased blood flow to the mammary glands, has been reported to be a risk factor for breast tuberculosis [8]. In endemic countries, tuberculous mastitis most commonly occurs in women of reproductive age, that is, those aged 20-40 years $[7,8]$. However, as in this case, tuberculous mastitis can occasionally occur in elderly patients [9] and sometimes even in men [7]. In a literature review of 12 cases of tuberculous mastitis between 1984 and 1994 in Japan, the mean age (range) of patients was reported to be 42.8 years (28-84 years) [9].

Tuberculous mastitis often mimics breast cancer because it frequently presents as a firm elastic mass lesion in the unilateral breast [6]. It is usually difficult to distinguish tuberculous mastitis from breast cancer based on ultrasonography and CT imaging $[4,5]$. A case of concurrent cancer and tuberculosis in the breast has also been reported. Therefore, clinicians should suspect breast tuberculosis when cytology-nonspecific and/or refractory mass-like lesions are present in the breast.

Although rare, it is important to recognize that tuberculous mastitis can present with refractory abscess or mass lesions that mimic carcinomas in the unilateral breast of women in the reproductive age group and elderly people. The diagnosis of breast tuberculosis might be delayed; hence, it should always be included in the differential diagnoses, particularly in patients with a history of tuberculosis or those living in areas where tuberculosis is endemic. 


\section{Abbreviations}

Received: 21 October 2019 Accepted: 31 January 2021

Published online: 04 March 2021

CT: Computed tomography; MRI: Magnetic resonance imaging.

\section{Acknowledgements}

Not applicable.

\section{Authors' contributions}

YS, AK, and MS cared for the patient and drafted the case report. YS and SH conducted this study and wrote the manuscript. SH and MM critically revised the entire manuscript for intellectual content. All authors read and approved the final manuscript.

\section{Funding}

No funding was received for this study.

\section{Availability of data and materials}

Not applicable.

\section{Ethics approval and consent to participate}

Not applicable.

\section{Consent for publication}

Written informed consent was obtained from the patient for publication of this case report and any accompanying images. A copy of the written consent is available for review by the Editor-in-Chief of this journal.

\section{Competing interests}

The authors declare that they have no competing interests.

\section{Author details}

1 Division of General Internal Medicine, Jichi Medical University Hospital, 3311-1 Yakushiji, Shimotsuke-shi, Tochigi 329-0498, Japan. ${ }^{2}$ Division of Infectious Diseases, Jichi Medical University Hospital, $3311-1$ Yakushiji, Shimotsuke-shi, Tochigi 329-0498, Japan. ${ }^{3}$ Division of Breast Surgery, Jichi Medical University Hospital, 3311-1 Yakushiji, Shimotsuke-shi, Tochigi 329-0498, Japan.

\section{References}

1. Angelopoulou A, Field D, Ryan CA, Stanton C, Hill C, Ross RP. The microbiology and treatment of human mastitis. Med Microbiol Immunol. 2018:207:83-94.

2. Ammari FF, Yaghan RJ, Omari AK. Periductal mastitis. Clinical characteristics and outcome. Saudi Med J. 2002;23:819-22.

3. Stary CM, Lee YS, Balfour J. Idiopathic granulomatous mastitis associated with Corynebacterium sp. Infection. Hawaii Med J. 2011;70:99-101.

4. Kilic MO, Saglam C, Agca FD, Terzioglu SG. Clinical, diagnostic and therapeutic management of patients with breast tuberculosis: analysis of 46 cases. Kaohsiung J Med Sci. 2016;32(1):27-31.

5. Longman CF, Campion T, Butler B, Suaris TD, Khanam A, Kunsr H, et al. Imaging features and diagnosis of tuberculosis of the breast. Clin Radiol. 2017;72:217-22.

6. Khanna R, Prasanna GV, Gupta P, Kumar M, Khanna S, Khanna AK. Mammary tuberculosis: report on 52 cases. Postgrad Med J. 2002;78:422-4.

7. Tewari M, Shukla HS. Breast tuberculosis; diagnosis, clinical features and management. Indian J Med Res. 2005;122:103-10.

8. Cakar B, Ciledag A. Retrospective analysis of seven breast tuberculosis cases. Exp Ther Med. 2016;12:3053-7.

9. Fukuoka K, Choh S, Hamada K, Yoneda T, Narita N. A case of tuberculosis of the breast review of the literature published during the last 10 years in Japan. Kekkaku. 1995;70:111-5.

\section{Publisher's Note}

Springer Nature remains neutral with regard to jurisdictional claims in published maps and institutional affiliations.
Ready to submit your research? Choose BMC and benefit from:

- fast, convenient online submission

- thorough peer review by experienced researchers in your field

- rapid publication on acceptance

- support for research data, including large and complex data types

- gold Open Access which fosters wider collaboration and increased citations

- maximum visibility for your research: over $100 \mathrm{M}$ website views per year

At BMC, research is always in progress.

Learn more biomedcentral.com/submissions 